\title{
ANALISA BIBLIOMETRIK PULSE OXIMETRY NON-INVASIVE: 2011-2020
}

\author{
Sudimanto \\ Sekolah Tinggi Manajemen Informatika dan Komputer LIKMI \\ Jl. Ir. H. Juanda 96 Bandung 40132 \\ sudianen@yahoo.com
}

\begin{abstract}
ABSTRAK
Tinjauan pustaka terhadap pulse oximetry dilakukan guna untuk melihat seberapa banyak publikasi yang telah. Tinjauan Pustaka ini menggunakan analisa bibliometrik yang mana analisanya dilakukan berdasarkan kata kunci pulse oximetry, non-invasive, blood saturation dan Oxygen. Analisa bibliometrik ini menggunakan aplikasi VOSviewer untuk memvisualisasikan berbagai macam bentuk keterhubungan baik antar penulis, negaranegara yang melakukan penelitian yang sama. Pada VOSviewer memvisualisasikan topik penelitian berdasarkan kata kunci didapat sebanyak 147 artikel yang dilihat dari judul dengan mengambil $60 \%$ dari 147 yaitu 88 topik yang memiliki tingkat relevansinya tinggi yaitu sebesar 2.13
\end{abstract}

Kata kunci: Bibliometrik, Non-Invasive , Oximetry, VOSviewer

\section{PENDAHULUAN}

Darah adalah cairan yang berada di dalam tubuh yang mana memiliki peranan yang cukup penting bagi kehidupan manusia. Fungsi darah hampir sama seperti air tetapi memiliki tingkat kekentalan yang berbeda dikarenakan di dalam darah mengandung banyak zat-zat penting yang untuk kelangsungan hidup manusia (Djie, 2020). Salah satu fungsi darah yaitu menghantarkan oksigen ke seluruh tubuh serta merupakan salah satu faktor penting untuk tetap hidup (Elagha et al., 2019).

Salah satu cara pengukuran kadar oksigen dalam darah adalah dengan menggunakan pulse Oximetry. Pulse oximetry merupakan sebuah metode pengukuran kadar oksigen secara non-invasive serta tidak menimbulkan rasa sakit pada penggunanya serta dapat digunakan untuk mendeteksi perubahan yang terjadi pada efisiensi dari aliran darah di dalam tubuh manusia terutama daerah yang jauh dari jantung (Umar et al., 2018).

Analisa jaringan yang dibentuk secara bibliometrik ini mampu mengenali area topik penelitian yang muncul serta mampu melakukan pengelompokkan terhadap bidangbidang penelitian dengan berbasiskan pada karakteristik dari penulis maupun institusi (Fahimnia et al., 2015). Analisa bibliometrik tentang pulse oximetry ini menggunakan sebuah perangkat lunak yang bernama VOSviewer. Data-data publikasi yang gunakan untuk melakukan analisa bibliometrik ini diambil dari database yang ada pada www.Dimensions.ai. Analisa bibliometrik yang dilakukan VOSviewer menggunakan metode perhitungan full counting. Metode full counting adalah jumlah bobot pada sebuah artikel yang ditulis bersama dihitung dengan bobot penuh satu, yang mana mengartikan bahwa bobot keseluruhan publikasi sama dengan jumlah publikasi (Perianes-Rodriguez et al., 2016).

\section{KONSEP ANALISA BIBLIOMETRIK PULSE OXIMETRY NON-INVASIVE}

Konsep dari analisa ini adalah dengan menggunakan berberapa kata kunci untuk mencari artikel-artikel penelitian yang dipublikasi secara international. Pengambilan data 
publikasi dilakukan di website www.Dimensions.ai. Kata kunci yang digunakan pada analisa ini adalah pulse oximetry, non-invasive, blood saturation, Oxygen. Tahun publikasi yang diambil berjarak 10 tahun yaitu dari tahun 2011 hingga 2020.

Hasil dari pencarian dapat ditampilkan secara grafik pada website itu sendiri, atau jumlah publikasi dari seluruh dunia serta dari berbagai macam bidang penelitian. Gambar 1 merupakan contoh dari hasil pencarian yang dilakukan pada database www.Dimension.ai dengan kata kunci pulse oximetry dengan rentan waktu artikel yang publikasi berjarak 10 tahun.

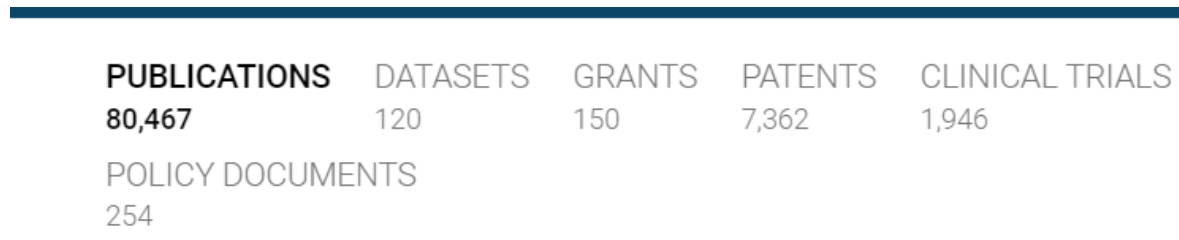

Gambar 1. Jumlah Publikasi dengan kata kunci Pulse Oximetry

Gambar 2 merupakan grafik batang pada www.Dimensions.ai yang mana grafik tersebut menunjukkan bidang-bidang penelitian yang pernah melakukan penelitian terhadap pulse oximetry.

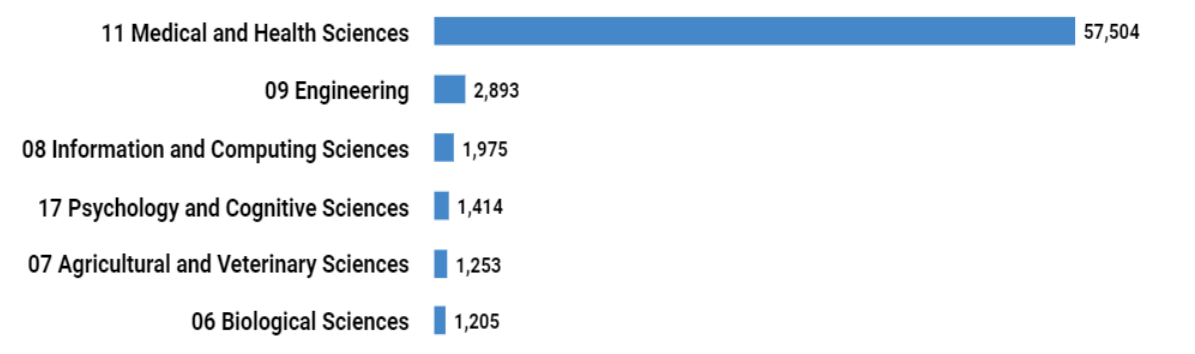

Gambar 2. Bidang Penelitian yang Melakukan Publikasi tentang Pulse Oximetry

\section{HASIL DAN PEMBAHASAN}

Analisa pada analisa bibliometrik ini adalah menggunakan jumlah artikel yang telah publikasikan, nama jurnal yang terbanyak yang banyak terpilih untuk mempublikasikan artikel dengan kata kunci yang sama serta nama penulis dan negara asal yang melakukan penelitian sesuai dengan kata kunci.

Kata kunci yang digunakan pada analisa ini adalah pulse oximetry, non-invasive, blood saturation dan Oxygen. Penghubung antar kata kunci menggunakan operator AND. Serta tahun publikasi yang dicari adalah antara tahun 2011-2020. Pencarian kata kunci dengan operator AND memiliki beberapa kombinasi tetapi yang digunakan pada analisis ini dapat dilihat pada Tabel 1.

Tabel 1. Jumlah Publikasi Berdasarkan Kata Kunci

\begin{tabular}{|l|c|}
\hline Kata Kunci & Jumlah Publikasi \\
\hline Pulse Oximetry & 80,467 \\
\hline Pulse Oximetry AND Oxygen & 62,414 \\
\hline Pulse Oximetry AND Blood Saturation & 44,967 \\
\hline $\begin{array}{l}\text { Pulse Oximetry AND Blood Saturation } \\
\text { AND Oxygen AND non-invasive }\end{array}$ & 24,371 \\
\hline Total & 212,219 \\
\hline
\end{tabular}


Pada tabel 1 menunjukan total jumlah publikasi yang telah dilakukan berdasarkan kata kunci dan rentan waktu publikasi. Jumlah publikasi pada tabel 1 adalah jumlah publikasi dari semua bidang penelitian seperti pada Gambar 3. Jumlah terbanyak publikasi berdasarkan kata kunci dilakukan di bidang Medical and Health Science yaitu sebanyak 14,273 publikasi dari 24,371 publikasi. Gambar 3 menunjukan pula 10 bidang penelitian yang teratas dengan kata kunci yang telah diberikan.

Bidang penelitian Information and Computing Science masih memiliki jumlah publikasi sebanyak 383 publikasi yang mana pada Information and Computing Science masih memiliki sub-bidang penelitian yang lainnya seperti pada Gambar 4.

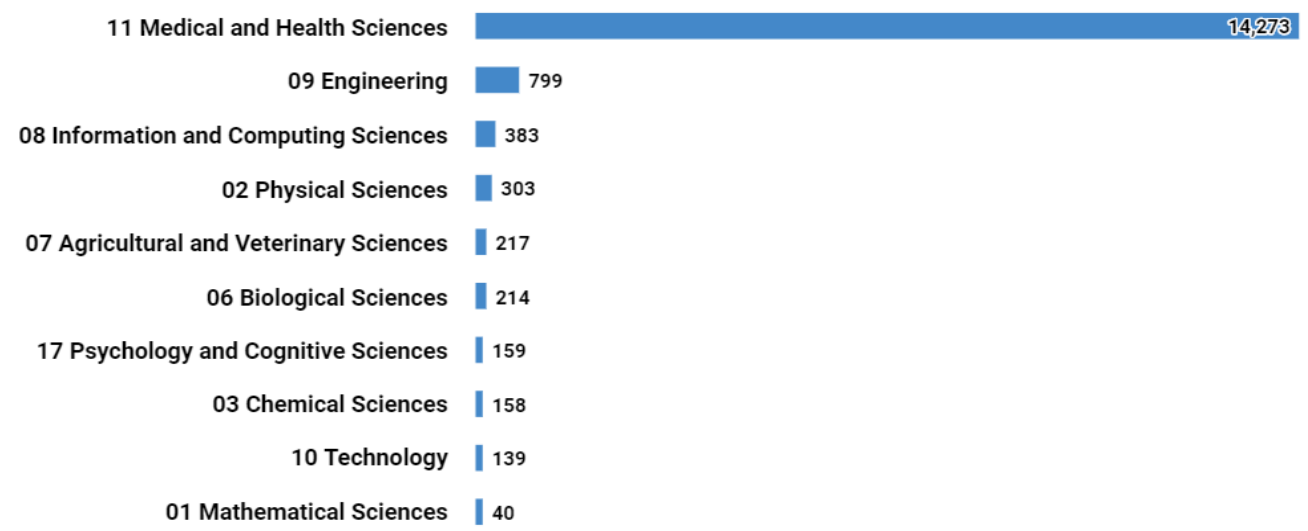

Gambar 3. Grafik Publikasi Berdasarkan Bidang Penelitian

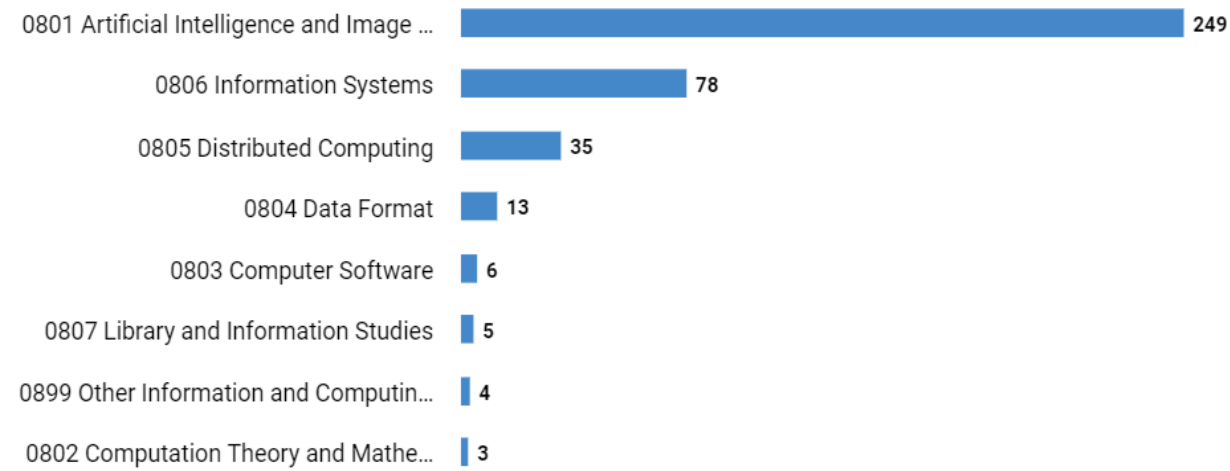

Gambar 4. Grafik Publikasi Berdasarkan Sub Bidang Penelitian untuk Information and Computing Sciences

Hasil pencarian artikel yang dipublikasikan berdasarkan kata kunci dan pada bidang penelitian Information and Computing Science serta dengan rentan waktu 10 tahun adalah sebanyak 383 publikasi. Data dari 383 publikasi ini akan diekspor dalam tiga file dengan extension yang berbeda. yaitu : CSV, RIS dan file bibliometric mapping yang khusus disediakan oleh www.Dimensions.ai untuk dipergunakan pada VOSviewer. Pada analisa ini menggunakan dua buah file yaitu bibliometric mapping yang khusus pergunakan untuk VOSviewer dan CiteSpace dengan berektension *.CSV dan file dengan ekstension *.RIS. Gambar 5. menunjukan kolaborasi antar penulis utama artikel dengan waktu penerbitan dari artikel yang berbeda-beda. 


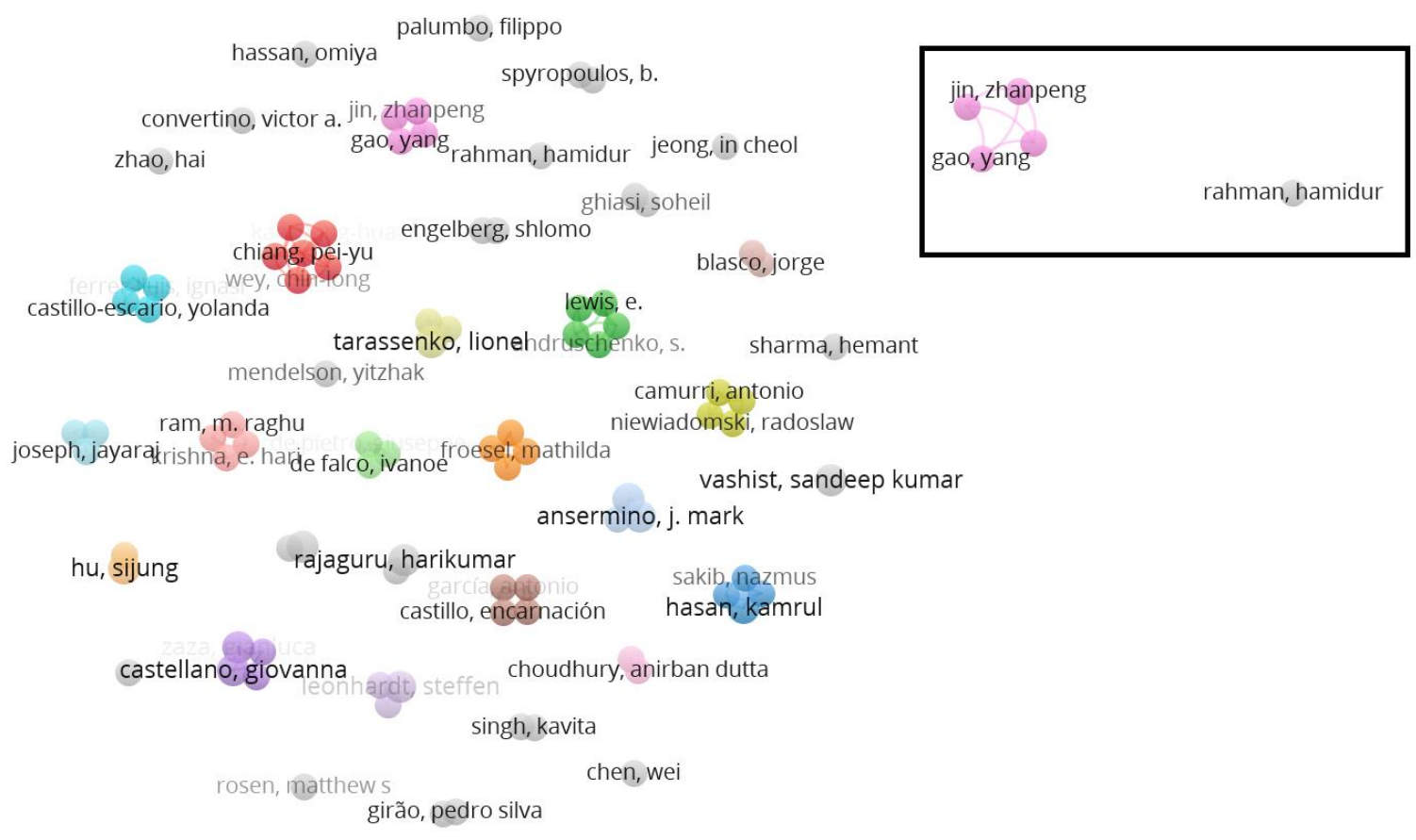

\section{Gambar 5. Kolaborasi Antar Penulis}

Gambar 5. juga menunjukkan bahwa dari semua penulis ada beberapa penulis yang tidak saling berkolaborasi seperti pada potongan gambar kecil yang terdapat pada gambar 5. Penulis bernama Zhanpeng Jin berkolaborasi dengan penulis Yang Gao, tetapi mereka tidak berkolaborasi dengan Hamidur Rahman. Dapat dikatakan pula Hamidur Rahman menulis artikel yang memiliki kata kunci sama seperti artikel yang Zhanpeng Jin dan Yang Gao.

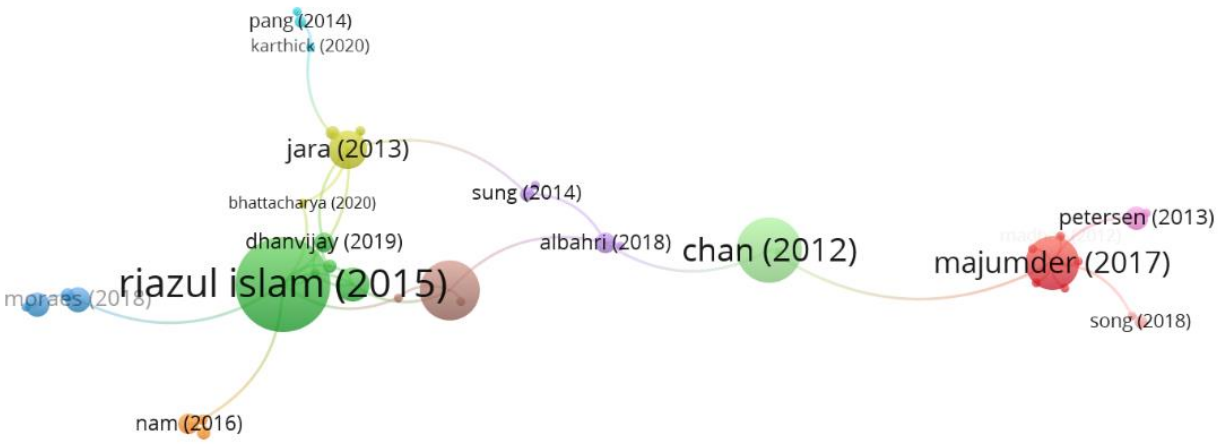

Gambar 6. Keterhubungan Penulis Berdasarkan Sitasi

Gambar 6. memperlihatkan kerterhubungan antar penulis berdasarkan hasil dari sitasi, yang dilakukan oleh penulis lain baik yang memiliki negara maupun organisasi yang sama dengan penulis yang disitasi. 


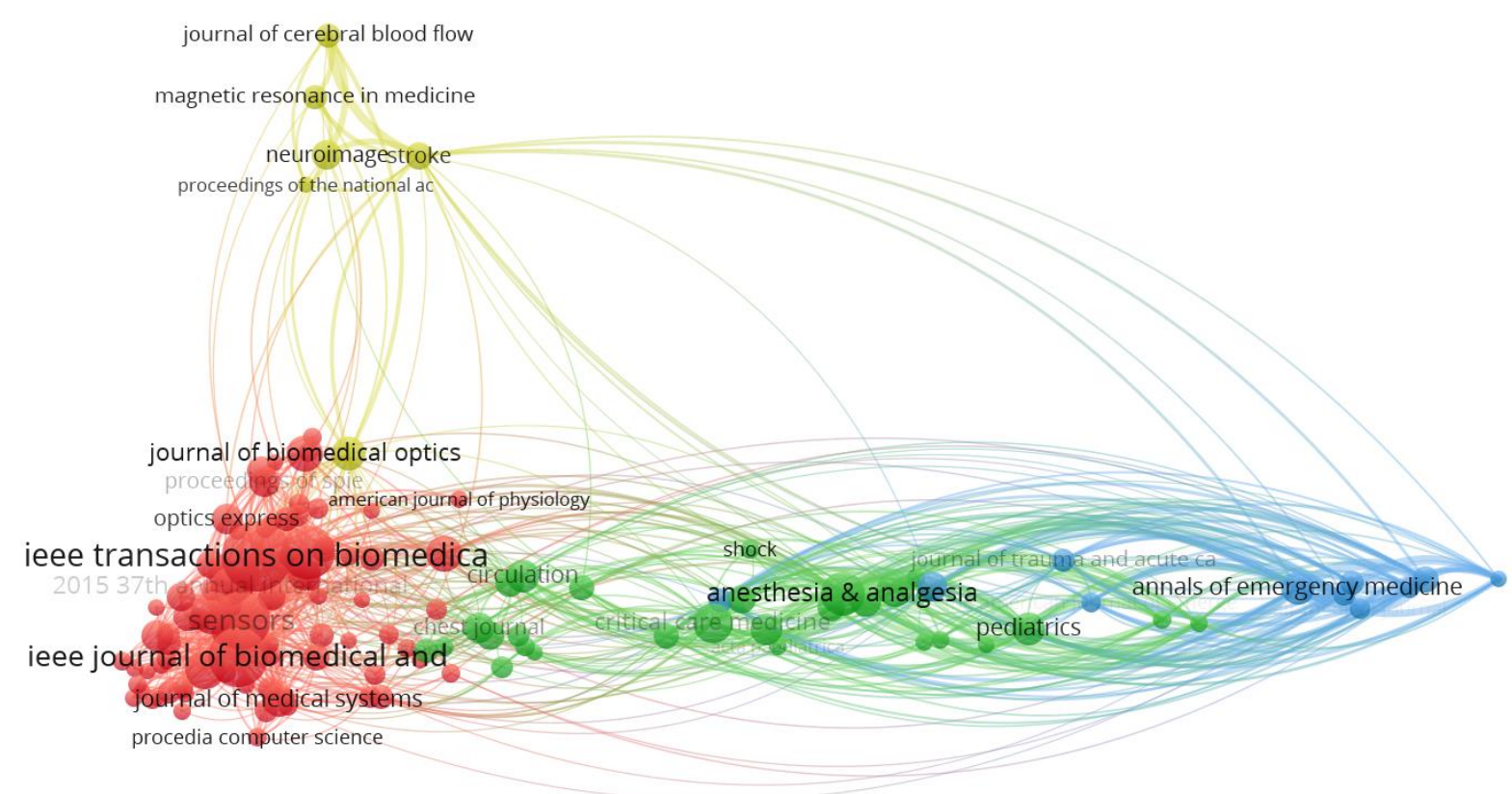

Gambar 7. Keterhubungan Berdasarkan Sumber Co-Citation

Gambar 7. merupakan hasil co-citation dengan tipe analisa adalah citied source, yang mengartikan bahwa hasil analisa yang ditunjukan pada gambar 7 merupakan sumber jurnal yang dikutip oleh para penulis.

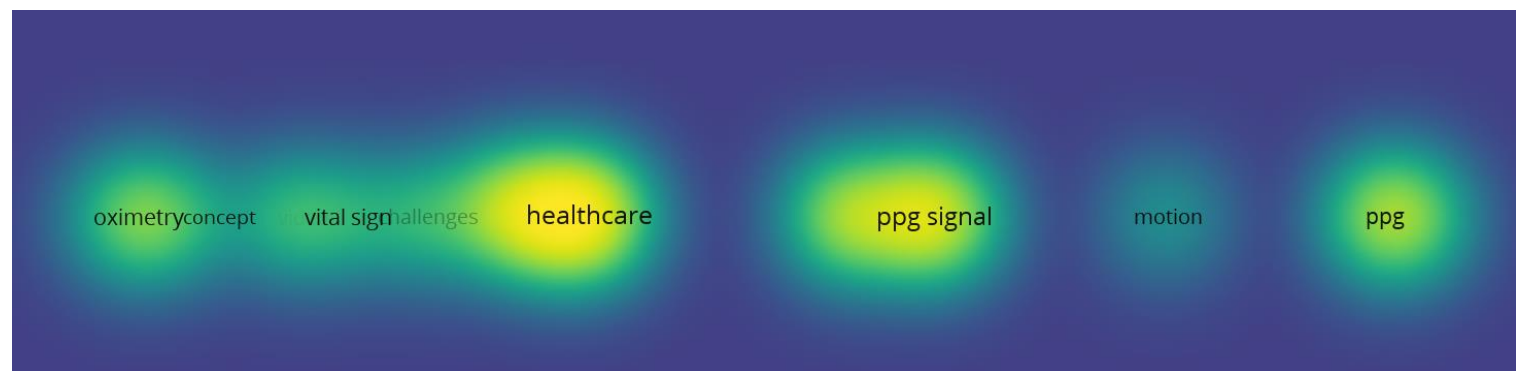

Gambar 8. Density Visualization Terhadap Bidang Penelitian Berdasarkan Judul

Gambar 8. merupakan bentuk visualisasi yang menunjukkan topik-topik penelitian terbanyak berdasarkan kata kunci yang dihubungkan dengan judul-judul penelitian. Dari kata kunci yang terdapat pada judul terdapat 147 publikasi yang memiliki istilah yang sesuai dengan kata kunci. Dari 147 publikasi ini akan diambil sebanyak 60\% yang mempunyai hubungan, maka hasil yang didapat sebanyak 88 istilah yang memiliki relevansi dari 0 hingga 2.13. Dari kata kunci yang berikan terdapat pengelompokan yang dilakukan berdasarkan judul artikel yang dipublikasikan sebanyak 7 pengelompokan.

\section{KESIMPULAN}

Berdasarkan hasil analisa maka dapat dikatakan bahwa pencarian artikel berdasarkan kata kunci dapat membantu para peneliti untuk menentukan penelitian yang nantinya akan dilakukan dengan melihat beberapa faktor seperti bidang penelitian atau ingin mengetahui jumlah publikasi terbanyak yang memiliki topik penelitian sesuai dengan kata kunci. Dari 147 publikasi yang memiliki kata kunci yang berada pada judul penelitian di dapat 88 istilah dalam publikasi yang memiliki kata kunci adalah pulse oximetry, non-invasive, blood saturation dan Oxygen serta pengelompokan yang dilakukan secara otomatis pada aplikasi VOSviewer terdapat 7 pengelompokkan berdasarkan judul artikel 


\section{DAFTAR PUSTAKA}

[1] Djie, An. (2020). Serba-Serbi Pengertian Darah, Cairan Vital di Tubuh Kita. https://www.sehatq.com/artikel/ini-dia-pengertian-darah-cairan-yang-vital-di-tubuhkita

[2] Elagha, A. Y. H., EL-Farra, A. A. H., \& Shehada, M. H. K. (2019). Design a NonInvasive Pulse Oximeter Device Based on PIC Microcontroller. 2019 International Conference on Promising Electronic Technologies (ICPET), 107-112. https://doi.org/10.1109/ICPET.2019.00027

[3] Fahimnia, B., Sarkis, J., \& Davarzani, H. (2015). Green Supply Chain Management: A Review And Bibliometric Analysis. In International Journal of Production Economics (Vol. 162). Elsevier. https://doi.org/10.1016/j.ijpe.2015.01.003

[4] Perianes-Rodriguez, A., Waltman, L., \& van Eck, N. J. (2016). Constructing Bibliometric Networks: A Comparison Between Full And Fractional Counting. Journal of Informetrics, 10(4), 1178-1195. https://doi.org/10.1016/j.joi.2016.10.006

[5] Umar, L., Firmansyah, I., \& Setiadi, R. N. (2018). Design of Pulse Oximetry Based on Photoplethysmography and Beat Rate Signal Using DS-100 Probe Sensor for SpO2 Measurement. ISSIMM 2018 - 3rd International Seminar on Sensors, Instrumentation, Measurement and Metrology, Proceeding, O(2), 44-47. https://doi.org/10.1109/ISSIMM.2018.8727725 